www.jmscr.igmpublication.org Impact Factor 5.244

Index Copernicus Value: 5.88 ISSN (e)-2347-176x ISSN (p) 2455-0450 crossref DOI:_http://dx.doi.org/10.18535/jmscr/v4i5.48

\title{
Evaluation of Various Etiological Factors \& Clinical Presentations of Epididymo-Orchitis at a Tertiary Care Centre (Original Article)
}

\author{
Authors \\ Navneet Parashar ${ }^{1}$, Shivraj Meena ${ }^{2}$, R.S Meena ${ }^{3}$ \\ ${ }^{1}$ Assistant Professor, Department of Surgery, NMCH, Govt Medical College Kota, Rajasthan, India \\ ${ }^{2}$ Assistant Professor, Department of Medicine, NMCH, Govt Medical College Kota, Rajasthan, India \\ ${ }^{3}$ Senior Professor \& HOD, Department of Surgery, Govt Medical College Kota, Rajasthan, India \\ Corresponding Author
}

Dr Navneet Parashar

Type II/ 09, medical college campus, Govt medical college

Rangbari road, Kota, Rajasthan, India Pincode-324005

Email-shivraj.aiims@gmail.com, Mobile-+919828589880

\begin{abstract}
Purpose- No Indian data exists on the incidence and prevalence of epididymo-orchitis. Western data suggest that the incidence of the disease is highest among young males aged between 18 and 35 years of age. Our aims were to establish various etiological factors in development of epididymo-orchitis.

Methods- This prospective study was conducted on 50 patients of Epididymitis / Epdididymo-orchitis Results: Most common age of presentation of epididymo-orchitis is between 30-50 years. Urinary complain is present in more than half (54\%) of patients at the time of presentation. In acute epididymo-orchitis, fever $(44 \%)$ and urethritis (17\%) were found commonly. Both epididymis and testis are involved in most of acute cases (95\%). While 33\% of chronic cases involved only epididymis E. coli was the most common organism which was isolated in urine cultures (57.8\% among the isolated organisms). Mycobacterium tuberculosis infection was found in around $10 \%$ of cases.
\end{abstract}

Conclusion: E. coli was the most common organism which was isolated in urine cultures. Early and proper empirical treatment (and later on according to culture sensitivity report) with bed rest and scrotal support should be started as early as possible. This prevents the complications and conversion to chronic form.

Key words- Epididymo-orchitis, Gonococcal urethritis, Chlamydia. Dysurea

\section{INTRODUCTION}

Acute epididymitis is a syndrome characterized by pain, swelling, and inflammation of the epididymis of less than 6 weeks duration. Its true incidence and prevalence in the general population are unknown, but it appears to occur with increased frequency among younger men (under the age of 40) ${ }^{1}$ and in men who engage in unprotected anal intercourse. ${ }^{2}$ Western data suggest that the incidence of the disease is highest among young males aged between 18 and 35 years of age. ${ }^{5,6}$. These two peaks can be explained 
by the fact that in young males epididymo-orchitis is usually secondary to STD (this age group being sexually active). Many cases of epididymitis are caused by $\mathrm{C}$ trachomatis and $\mathrm{N}$ gonorrhoeae. It is likely that there is a recent increase in cases of epididymitis that parallels the increase in reported cases of Chlamydia infection and gonorrhea in the United States (increases of $5.6 \%$ and $5.5 \%$, respectively, from 2005 to 2006). ${ }^{3}$

The cause of acute epididymitis can be infectious or noninfectious; most cases are infectious in origin. Although the pathophysiology is still unproven, the most commonly accepted hypothesis is retrograde flow of infected urine into the ejaculatory duct. ${ }^{4}$ No Indian data exists on the incidence and prevalence of epididymo-orchitis. In older males the disease occur secondary to UTI due to urinary obstruction in old age or due to instrumentation. $^{7}$ As the incidence of STD is high among indian males, ${ }^{8,16}$ it can be derived that the incidence of epididymo-orchitis will also be high. In present study our aims was to establish various etiological factors in development of epididymoorchitis. Role of pre-existing urinary tract infections, obstructive uropathy in development of epididymo-orchitis, instrumentations, indewelling catheters and ureteric stents, in development of epididymo-orchitis. Role of tuberculosis in development of epididymo-orchitis. Role of starting early empirical antibiotics to prevent complications.

\section{MATERIAL AND METHODS}

This prospective study was conducted on 50 patients of Epididymitis / Epdididymo-orchitis admitted in surgical / Medical wards of new medical college hospital, Govt medical college kota between march 2015 to February 2016.

A written informed consent was taken from each cases included in the study after thorough counseling. All cases were selected, taking into consideration the inclusion \& exclusion criteria. Inclusion criteria were clinically and / or ultrasonographically diagnosed cases of epididymo-orchitis / epididymitis or orchitis were included in the study. Exclusion criteria were a case of scrotal swelling other than epididymoorchitis were excluded on basis of physical examination and USG reposts (like - torsion testis.), Epididymal cyst.

A detailed history was taken, history of pain \& swelling in scrotum, dysurea, fever, urethral discharge. History of trauma, retention urine and instrumentation.

History of recent sexual contact, multiple sexual partners, PID in spouse, urgency / frequency / poor stream urine, contact with patient of tuberculosis, animal exposure, rash with or without fever. History of medication, hematuria / chylura and genital ulceration.

On local examination following were seen. On inspection, unilateral / bilateral swelling, condition of scrotum, colour/ edematous/ glossy, signs of inflammation, size shape of swelling, reducibility on lying down, cough impulse and any mucocutaneous / genital lesion.

On palpation, temperature was normal / raised, tender / non tender, get above the swelling was present or not, prehn's test (to exclude torsion testis). Surface of swelling was smooth or cragging, fluctuation, transilumination and involvement of epididymis / testis.

On investigations- CBC, blood sugar, urea creatinine. ESR, HIV I / II, VDRL, HBs Ag, urine examination - complete \& microscopy, culture and sensitivity, urethral discharge (urethral swab) (gram staining, AFB staining, culture / sensitivity), sputum for AFB. Semen ( For ABF, sperm counts). Blood culture, mantoux test, x-ray chest (TB focus or hilar lymphademopathy), USG with / without colour doppler study, FNAC / biopsy.

All admitted patients of epididymo-orchitis prophylactic injection ceftriaxon, Igm IV BD. Amikacin 500 IV BD; non-steroidal antiinflammatory drug bed rest scrotal support and IV fluid (if required) was started empirically. Tab ofloxacin $400 \mathrm{mg}$ BD or doxycycline $100 \mathrm{mg}$ BD started in presence of urethritis or history of PID in spouse or unprotected sexual exposure then 
antibiotic was added on the basis of culture and sensitivity reports. Anti tubercular treatment was carried out in suspected / diagnosed cases of tubercular epididymo-orchitis. Incision and Drainage was done in required patients. Epdidymectomy / orchidectomy were done in non-responded patients.

\section{RESULT}

In our study $41(82 \%)$ were acute EpididymioOrchitis and $9(18 \%)$ were chronic EpididymioOrchitis cases. Most common age of presentation is 41-50 years was 12 in acute \& 4 in chronic cases. In 21-30 \& 31-40 years age group, acute \& chronic were $6(14.63 \%) \& 1(11.11 \%)$ and 9 $(21.95 \%) \& 4(44.44 \%)$ respectively. (Table 1$)$

In our study both epididymis and testis are involved in most of the acute cases. 39 (95.12\%) out of 41 cases were of acute epididymo-orchitis while only $2(4.87 \%)$ cases out of 41 were of orchitis. While in chronic form of the disease $33 \%$ (3 out of 9) were of epididymis without involvement of testis and rest $66 \%$ has epididymoorchitis. No case was found of chronic orchitis. (Table 2)

In our study distribution of cases according to side Involved, on right side 22 (44\%); left side 20 $(40 \%)$ and bilateral $8(16 \%)$.Both sides are almost equally involved.

In our study pain, swelling, urinary complain, fever and discharge per urethra in acute $\&$ chronic Epididymio-Orchitis were 41\&9, 41\&9, 22\& 5, $18 \& 2$ and $7 \& 0$ respectively. Most common presentation was pain and swelling in our study. (Table 3)

In our study most cases were presented with dysurea, which was $22(53.65 \%)$ in acute and 5 $(55.55 \%)$ in chronic epididymo-orchitis cases. Obstructed uropathy \& Instrumentation/ Catheterization in acute \& chronic EpididymioOrchitis were $10(24.39 \%) \quad \& 1 \quad(11.11 \%)$ respectively. Prostatitis was $7(17.07 \%)$ in acute and $2(22.22 \%)$ in chronic cases. Diabetes was present only in 2 cases. Trauma and parotitis were in single cases only. (Table 4)
In our study $34(82.92 \%)$ acute cases had pus cell in urine where as $6(66.88 \%)$ in chronic cases. 9 acute cases had RBC in urine Per HPF where as 2 in chronic cases. 24 acute cases had TLC increased $>10,000$ /cumm where as 2 in chronic cases. Three acute cases had Evidences of mycobacterium tuberculosis where as 2 in chronic cases. VDRL Positive (1), Gonococcal urethritis (1), Non-Gonococcal urethritis (6) were seen in only acute cases. (Table 5)

Urine culture was positive in 15 cases, out of 41 cases in acute epididymo-orchitis patients. E. coli (26.82\%) was most common organism found on culture of urine. Urine culture was positive in 4 cases, out of nine cases in chronic epididymoorchitis patients. (Table 6)

Sexual transmitted disease was found in 8 cases out of 41 cases of acute epididymo-orchitis. Out of them $6(14.63 \%)$ case were found to be of non gonococcal urethritis one case was gonococcal urethritis and one case was of syphilis (VDRL and TPHA positive). (Table 7)

In acute disease, 11 cases out of 41 (acute epididymo-orchitis) developed complications (26.82\%). In acute epididymo-orchitis, common complication were Acute converted in chronic disease/ recurrent (3), abscess (3), testicular infarction (3), and opposite site involved (2).Chronic disease, 4 cases out of 9 developed complications (44.44\%). In chronic epididymoorchitis, common complication were abscess (2), Non responsive to medical management (Epididymectomy/ Orchidectomy done) (2).Total 15 cases $(30 \%)$ developed complications. (Table 8). 
Table1; Distribution of epididymo-orchitis cases according to age group.

\begin{tabular}{|l|c|c|c|}
\hline Age & $\begin{array}{c}\text { Acute } \\
(\mathrm{n}=41)\end{array}$ & $\begin{array}{c}\text { Chronic } \\
(\mathrm{n}=9)\end{array}$ & Total \\
\hline$<10$ & $0(0 \%)$ & $0(0 \%)$ & $0(0 \%)$ \\
\hline $11-20$ & $5(12.19 \%)$ & $0(0 \%)$ & $5(10 \%)$ \\
\hline $21-30$ & $6(14.63 \%)$ & $1(11.11 \%)$ & $7(14 \%)$ \\
\hline $31-40$ & $9(21.95 \%)$ & $4(44.44 \%)$ & $13(26 \%)$ \\
\hline $41-50$ & $12(29.26 \%)$ & $4(44.44 \%)$ & $16(32 \%)$ \\
\hline $51-60$ & $5(12.19 \%)$ & $0(0 \%)$ & $5(10 \%)$ \\
\hline$>60$ & $4(9.75 \%)$ & $0(0 \%)$ & $4(8 \%)$ \\
\hline Total & $41(82 \%)$ & $9(18 \%)$ & $50(100 \%)$ \\
\hline
\end{tabular}

Table 2; Distribution of epididymo-orchitis cases by involvement of Epididymis and Testis

\begin{tabular}{|l|c|c|c|}
\hline & Acute & Chronic & Total \\
\hline Only Epididymitis & $0(0 \%)$ & $3(33.33 \%)$ & $3(6 \%)$ \\
\hline Epididymio-Orchitis & $39(95.12 \%)$ & $6(66.66 \%)$ & $45(90 \%)$ \\
\hline Only Orchitis & $2(4.87 \%)$ & $0(0 \%)$ & $2(4 \%)$ \\
\hline Total & $41(100 \%)$ & $9(100 \%)$ & $50(100 \%)$ \\
\hline
\end{tabular}

Table 3; Distribution of epididymo-orchitis cases according to sign \& symptoms

\begin{tabular}{|l|c|c|c|}
\hline Sign / Symptoms & Acute $(\mathrm{n}=41)$ & $\begin{array}{c}\text { Chronic } \\
(\mathrm{n}=9)\end{array}$ & $\begin{array}{c}\text { Total } \\
50\end{array}$ \\
\hline Pain & $41(100 \%)$ & $9(100 \%)$ & $50(100 \%)$ \\
\hline Swelling & $41(100 \%)$ & $9(100 \%)$ & $50(100 \%)$ \\
\hline $\begin{array}{l}\text { Urinary complain (dysurea / Burning } \\
\text { micturation) }\end{array}$ & $22(53.65 \%)$ & $5(55.55 \%)$ & $27(54 \%)$ \\
\hline Fever & $18(43.90 \%)$ & $2(22.22 \%)$ & $20(40 \%)$ \\
\hline Discharge per urethra & $7(17.07 \%)$ & $0(0 \%)$ & $7 \quad(14 \%)$ \\
\hline
\end{tabular}

Table 4; Distribution of epididymo-orchitis cases according to History and Clinical Examination

\begin{tabular}{|l|c|c|cc|}
\hline & Acute $(\mathrm{n}=41)$ & Chronic $(\mathrm{n}=9)$ & \multicolumn{2}{|c|}{ Total $(\mathrm{n}=50)$} \\
\hline Dysurea & $22(53.65 \%)$ & $5(55.55 \%)$ & $27(54 \%)$ \\
\hline Urethritis & $7(17.07 \%)$ & $0(0 \%)$ & 7 & $(14 \%)$ \\
\hline Prostatitis & $7(17.07 \%)$ & $2(22.22 \%)$ & 9 & $(18 \%)$ \\
\hline Obstructed uropathy & $10(24.39 \%)$ & $1(11.11 \%)$ & 11 & $(22 \%)$ \\
\hline Instrumentation/ Catheterization & $10(24.39 \%)$ & $1(11.11 \%)$ & 11 & $(22 \%)$ \\
\hline $\begin{array}{l}\text { PID in spouse or Multiple } \\
\text { sexual partners }\end{array}$ & $5(12.19 \%)$ & $22(22.22 \%)$ & 7 & $(14 \%)$ \\
\hline Diabetes & $1(2.43 \%)$ & $1(11.11 \%)$ & 2 & $(4 \%)$ \\
\hline Trauma & $1(2.43 \%)$ & $0(0 \%)$ & 1 & $(2 \%)$ \\
\hline Parotitis & $1(2.43 \%)$ & $0(0 \%)$ & 1 & $(2 \%)$ \\
\hline Genital Ulcer & - & - & & - \\
\hline Rash / Purpura & - & - & \multicolumn{2}{|c|}{-} \\
\hline Drug (Amiodarone) & - & - & & \\
\hline
\end{tabular}


Table 5; Distribution of epididymo-orchitis cases according to Laboratory Investigations

\begin{tabular}{|c|c|c|c|}
\hline Investigations & Acute $(n=41)$ & Chronic $(\mathrm{n}=9)$ & $\begin{array}{l}\text { Total } \\
(\mathrm{n}=50)\end{array}$ \\
\hline \multirow{3}{*}{$\begin{array}{lr}\text { Pus cell Urine /HPF } & <5 \\
& 5-10 \\
& >10\end{array}$} & $9(21.95 \%)$ & $4(44.44 \%)$ & $13(26 \%)$ \\
\hline & $11(26.82 \%)$ & $0(0 \%)$ & $11(22 \%)$ \\
\hline & $14(34.14 \%)$ & $2(22.22 \%)$ & $16(32 \%)$ \\
\hline $\mathrm{RBC}$ in urine Per HPF & $9(21.95 \%)$ & $2(22.22 \%)$ & $11(22 \%)$ \\
\hline Organism isolated in urine culture & $14(34.14 \%)$ & $4(44.44 \%)$ & $18(36 \%)$ \\
\hline TLC increased $>10,000 /$ cumm & $24(58.53 \%)$ & $2(22.22 \%)$ & $26(52 \%)$ \\
\hline $\begin{array}{l}\text { Evidences of mycobacterium } \\
\text { tuberculosis }\end{array}$ & $3(7.31 \%)$ & $2(22.22 \%)$ & $5 \quad(10 \%)$ \\
\hline VDRL Positive & $1(2.43 \%)$ & - & $(2 \%)$ \\
\hline Gonococcal urethritis & $1(2.43 \%)$ & - & $(2 \%)$ \\
\hline Non-Gonococcal urethritis & $6(14.63 \%)$ & - & $6 \quad(12 \%)$ \\
\hline
\end{tabular}

Table 6; Distribution of epididymo-orchitis cases by organism identified on culture

\begin{tabular}{|l|c|c|}
\hline Organism & $\begin{array}{c}\text { Acute } \\
(\mathrm{n}=41)\end{array}$ & $\begin{array}{c}\text { Chronic } \\
(\mathrm{n}=9)\end{array}$ \\
\hline E Coli & $11(26.82 \%)$ & $0(0 \%)$ \\
\hline Proteus & $2(4.86 \%)$ & $0(0 \%)$ \\
\hline Pseudomonas & $1(2.43 \%)$ & $1(11.11 \%)$ \\
\hline S. aureus & $1(2.43 \%)$ & $1(11.11 \%)$ \\
\hline Citobactor & $0(0 \%)$ & $1(11.11 \%)$ \\
\hline Candida & $0(0 \%)$ & $(11.11 \%)$ \\
\hline
\end{tabular}

Table 7; Distribution of epididymo-orchitis cases according to sexually transmitted disease

\begin{tabular}{|l|c|c|}
\hline & Acute $(\mathrm{n}=41)$ & Chronic $(\mathrm{n}=9)$ \\
\hline VDRL & $1(2.43 \%)$ & $0(0 \%)$ \\
\hline Gonococcal urethritis & $1(2.43 \%)$ & $0(0 \%)$ \\
\hline Non Gonococcal urethritis & $6(14.63 \%)$ & $0(0 \%)$ \\
\hline
\end{tabular}

Table 8; Distribution of epididymo-orchitis cases according to Complications

\begin{tabular}{|l|c|c|c|}
\hline Complications & $\begin{array}{c}\text { Acute } \\
(\mathrm{n}=41)\end{array}$ & $\begin{array}{c}\text { Chronic } \\
(\mathrm{n}=9)\end{array}$ & $\begin{array}{c}\text { Total } \\
(\mathrm{n}=50)\end{array}$ \\
\hline Acute converted in chronic disease/ Recurrent & 3 & 0 & $3(6 \%)$ \\
\hline Opposite site involved & 2 & 0 & $2(4 \%)$ \\
\hline Abscess & 3 & 2 & $5(10 \%)$ \\
\hline Testicular infarction & 3 & 0 & $3(6 \%)$ \\
\hline $\begin{array}{l}\text { Non responsive to medical management } \\
\text { (Epididymectomy/ Orchidectomy done) }\end{array}$ & 0 & 2 & $2(4 \%)$ \\
\hline Total & $11(26.82 \%)$ & $4(44.44 \%)$ & $15(30 \%)$ \\
\hline
\end{tabular}

\section{DISCUSSION}

Most common age of presentation of epididymoorchitis is 30-50 years. 29 cases $(58 \%)$ are included in this group. 21 out of 41 cases of acute epididymo-orchitis were in this age group while 8 out of 9 cases of chronic epididymo-orchitis were in this age group. 9 out of 41 cases of acute epididymo-orchitis were $>50$ years of age. 22 out of 50 cases were equal or less than 35 years while 28 out of 50 cases were of more than 35 year of age.

While in study of Thomas $\mathrm{H}$. Trojan et al ${ }^{9}$ most common age of presentation is 14 to 35 years of men showing involvement of higher age group in 
Indian population by the disease. In study of A.A. Hoosen et al ${ }^{10}$ the majority of patients (93\%) were of age less than 35 year. While in this study only $44 \%$ of patients were below 35 years. Presentation of the disease was in acute form $(<6$ wks) in $41(82 \%)$ out of 50 cases while in chronic form in 9 cases $(18 \%)$.

Pain and swelling was most common presentation in both acute and chronic form of the disease. No case was presented with bursting or sinus of the scrotum might be due to early consultation and use of antibiotics by the patient suggesting improvement in the medical awareness. In study D. A. Hawkins et al ${ }^{12}$ showed In an 18 month period, 198 men presented with a painful, swollen, and tender epididymis or testicular or scrotal pain. $22(44 \%)$ out of 50 cases presented with pain and swelling in hemiscrotum in right side; 20 (40\%) out of 50 cases presented with left side involvement while $8(16 \%)$ out of 50 were bilateral at the time of presentation which were all acute cases. suggesting slight right prediction of the disease. Not a single case of chronic disease was bilateral. In D. A. Hawkins et $\mathrm{al}^{12}$ showed 40 men were seen who had acute unilateral epididymitis.Both epididymis and testis was involved in most of the acute cases. 39 (95\%) out of 41 cases were acute epididymo-orchitis while only $2(5 \%)$ cases out of 41 were of orchitis and no case was found of purely acute epididymitis while in chronic form of the disease $33 \%$ cases ( 3 out of 9) were of epididymitis without involvement of testis while rest were $66 \%$ (6 out of 9) have epididymo-orchitis while no case was found of the chronic orchitis.

While organism was identified on culture in 15 $(37.3 \%)$ cases. In 11 cases out of 15, E. Coli was found $(73.5 \%)$. Proteus specimen was found in 2 cases while pseudomonas specimen and staph epidermidis was found in one case. In Melekos MD et al $^{13}$ showed that The microbiological data showed a prevalence of Chlamydia trachomatis epididymal infections in men less than 40 years old, whereas common urinary tract pathogens prevailed in older patients.
Thus evidence of urinary tract infection (significant pus cell >10 HPF and organ isolation was found in $26(63.4 \%)$ out of 41 cases. While in chronic cases, burning micturation or dysurea was found in $5(55.5 \%)$ out of 9 cases, out of them 2 patients have both burning micturation with fever $22.2 \%$.Significant pus cell in urine $>10 \mathrm{HPF}$ was present in $2(22.2 \%)$ out of 9 cases. On culture microorganism was identified in $4(44.4 \%)$ out of 9 cases which were pseudomonas (1 case) staph aureus (1 case), citobactor ( 1 case) and candida (1 case).

Thus 30 cases out of $50(60 \%)$ showed evidence of urinary tract infection in epididymo-orchitis patients. Urethral discharge was present 7 cases out of 41 all were of acute cases. 6 out of them were $<35$ year of age $(85.7 \%)$.Four out of them had history of vaginal discharge in their spouses.On urine analysis 4 of them has $<5 \mathrm{HPF}$ pus cell in urine RBC was present in urine only in one case.In only one case staff epidermidis was found in culture of urine.On Gram staining of urethral discharge inflammatory cell were present in significant number while on culture only one case gram negative diplococci was identified suggestive of gonococcal urethritis while others in which organism was not identified may be probably of Chlamydia urethritis (confirmation test for Chlamydia sp. was not performed.)

With comparison to the study of A.A. Hoosen et al ${ }^{10}$ Neisseria gonococcus and Chlamydia were detected in $78 \%$ of cases. N. Gonococcus in $57 \%$ Chlamydia trachomatis in $34 \%$ and both in $13 \%$ and $93 \%$ patient were age of below 35 years. While in this study only $44 \%$ (22 cases) patient were of group $<35$ years of age. In 6 cases out of them (22 cases $<35$ years) urethritis was found. And only one case Neserria gonococcus was identified : and rest of them were of non gonococcus urethritis (most probably of Chlamydia infection on presumption). In Yamanoto $\mathrm{M}$ et al ${ }^{14}$ showed that an infective cause was identified in $56 \%$ of the patients. The most common microorganism was Chlamydia trachomatis. This microorganism was identified 
from urethral swabs in 11 patients (34\%). A total of 18 sexual partners were traced and investigated for chlamydia antigen by cervical swab, urinary bacterial culture, and chlamydia serologic testing. Of the 18 female sexual partners screened, 9 were partners of patients with chlamydial epididymitis; $78 \%$ of these women had the same infection.

While only one case out of 28 cases urethral discharge was found in $>35$ years who was diagnosed as non gonococal urethritis. Two case out of 41 was presented with only orchitis without epididymitis in which only one has history of sexual contact, constitutional features, lymphadenopathy, VDRL and TPHA positive suggestive of syphilis. Twelve cases out of 50 (24\%) case has history of obstructive uropathy or instrumentation and catheterization . Out of them 7 case were of prostatism, 4 case of stricture urethra one case was of $\mathrm{FuC}$ of laparotomy in which catheterization was done, out of 12 case 11 case of acute epididymo-orchitis while only one case was of chronic epididymo-orchitis. Whereas Melekos MD ${ }^{13}$ et al in 1987 published about etiological and treatment aspects of epididymitis. Extended microbiological studies were performed on 49 patients with acute or chronic epididymitis, including bacteriology of epididymal specimens in cases of scrotal surgery. In no patient had instrumentation or catheterization resulted in epididymitis.

On urine analysis 9 out of 12 case has significant pus cell were present and organism was isolated in 6 cases $(50 \%)$ in 5 case it was E. Coli and in one case proteus species was isolated.Seven cases out of 9 older than 50 year of age have bladder out let obstruction (BPH).On comparison in study of Edmud S Sabanegh B Jr ${ }^{9}$ et al $201056 \%$ of cases older than 60 years exhibit concurrent bladder out let obstruction like BPH or stricture urethra.Five cases out of $50(10 \%)$ showed evidence of mycobacterial tuberculosis infection associated with epididymo-orchitis, 3 out of 41 acute epididymo showed evidence of (7.3\%) Tuberculosis. For them ATT was started. 3 out of 9 cases $(33 \%)$ chronic epididymo-orchitis showed evidences of mycobacterium tuberculosis infection like raised ESR, on FNAC diagnosis was confirmed. In one case ATT was started and in another case ATT was not responsive. So epididymectomy was done. In third case I and D done, pus was found positive for AFB. Huan-Yun lin et al ${ }^{15}$ published a case report on tubercular epididymitis in Asian Journal of Andrology in 2005 showed that Tuberculous epididymitis is a rare urological disease difficult to diagnose.

Significantly raised leukocyte counts $(>10,000 \mathrm{Cu}$ $\mathrm{mm}$ ) was found in $26(52 \%)$ out of 50 cases 24 out of 41 cases of acute epididymo-orchitis (58.5\%) while in 2 cases (22\%) 7 chronic epididymoorchitis). Suggestive of systemic bacterial infection.Diabetics was found in 2 cases out of 50 (4\%) associated with raised sugar level in blood and urine one was acute another was chronic cases with significant finding on urine analysis.Acute epidymo-orchitis was associated with parotid enlargement in single case (1/50) who was a 12 year child who was not vaccinated (on history basis) with MMR vaccine. He was febrile with nonsignificant urine findings and without leucocytosis it was unilateral (right side). Compare with study of Beard C.M. et al ${ }^{11}$ now mump orchitis are rare because of MMR vaccination.

Out of 50 cases of epididymo-orchitis only single case of trauma was found. There was only pain and swelling, no fever, burning micturation leycocytosis, pus cell was present and no any organism was identified on urine culture reports. Six case out of 41 (14.6\%) develop complication 3 developed testicular abscess for $(7.3 \%)$ that incision and drainage was done and proper antibiotic coverage was continued till swelling subsided. 3 (7.3\%) developed testicular infraction even after continuation of antibiotic for that orchidectomy was done.

In chronic cases 2 out of 9 (22\%) developed testicular abscess for that incision and drainage was done. Out of two chronic case of epididymitis one was tubercular (FNAC proved) not responded to anti tubercular treatment for that 
epididymectomy was done while another non tubercular epididymits not responded to medical management and finally epididymectomy was done. Thus operative procedure was done in 10 $(20 \%)$ out of 50 cases of epididymo-orchitis patients. In 5 cases (10\%) I and D were done and in $5 \%$ case epididymectomy / orchidectomy was performed.

Conclusion: E. coli was the most common organism which was isolated in urine cultures. Early and proper empirical treatment (and later on according to culture sensitivity report) with bedrest and scrotal support should be started as early as possible. This prevents the complications and conversion to chronic form. Whenever the suspicion of mycobacterium tuberculosis infection diagnosis should be confirmed as early as possible and ATT is started. If there are evidences of pus collection, incision and drainage are done promptly.

\section{ACKNOWLEDGEMENTS}

Authors are thankful to medical and nursing staff of the medicine ward for their cooperation in the study.

Funding: No funding sources

Conflict of interest: None declared

Ethical approval: The study was approved by the institutional ethics committee.

\section{REFRENCES}

1. Mittemeyer BT, Lennox KW, Borski AA. Epididymitis: a review of 610 cases. J Urol. 1966;95:390-392.

2. Berger RE, Kessler D, Holmes KK. Etiology and manifestations of epididymitis in young men: correlations with sexual orientation. J Infect Dis. 1987; 155:1341-1343.

3. Centers for Disease Control and Prevention. Trends in Reportable Sexually Transmitted Diseasesin the United States, 2006. Atlanta: Centers for Disease Control and Prevention, Dept of Health and Human Services; November 2007.

4. Tracy CR, Steers WD, Costabile R. Diagnosis and management of epididymitis. Urol Clin North Am. 2008;35:101-108.

5. National Center for Health Statistics. [Internet] National Ambulatory Medical Care Survey, 2002. Available from: http://www.cdc.gov/nchs/about/major/ahc d/ahcd1.htm.

6. Kaver I, Matzkin H, Braf ZF. Epididymoorchitis: a retrospective study of 121 patients. J Fam Pract. 1990;30(5):548-552.

7. Williams RD, Cooper CS, Donovan JF. Acute Epididymitis. In: Current surgical diagnosis and treatment. Way LW, Doherty GM, editors. New York: Mc Graw Hill; 2002. p.1040.

8. WHO. Tackling the sexually transmitted diseases in the periphery, the syndromic approach. 2006;2.

9. Thomas H Trojian, Timothy S Lishnak Diana Heiman 2009 Apr : an overview epididymitis and orchitis; Am Fam Physician 2009 April 79(7) ; 583-7, 19378875.

10. A.A. Hoosen, NO Farrel, J Van Den Ende. Microbiology of acute epididymitis in a developing community. Genitourin Med. 1993 Oct;69(5):361-3.

11. C.M. Beard R.C. Benson Jr. P P Kelalis LR Elveback LT Kurland; Incidence and outcome of mumps orchitis in Rochester Minnesota 1935 to 1974 ; Mayo Clinic Prov 1977 Jan ; 52(1) 3-7 609284 Cit 36.

12. D A Hawkins, D Taylor Robinson, B.J. Thomas JR Harris ; Microbiological survey of acute epididymitis. Genitourin Med. 1986 Oct; 62(5): 342-344.

13. Melkos MD, Asbach HW; Epididymitis aspects concerning etiology and treatment J. Urol; 1987 Jul : 138 (1) 83-6.

14. Yamamoto M Hibi M Miyake K. dept of urology, Nagoya University of medicine 
Chlamydia trachomatis infection in young men with acute epididymitis and their sexual partner; Hinyokika Kiyo 1993; Sep 39(9): 819-22.

15. Huan-Yun Liu ; Yian-Tzueng Fu, ChingJiunn Wu Guang-Huan Sun. Tuberculous epididymitis ; A case report and literature review ; Asian Journal of Andrology (2005) 7, 329-332.

16. Thappa DM, Kaimal S. Sexually transmitted infections in India: Current status except human immunodeficiency virus/acquired immunodeficiency syndrome). Indian J dermatol 2007; 52:78-82. 